\title{
ADAPTIVE TRIMMED MEAN AUTOREGRESSIVE MODEL FOR REDUCTION OF POISSON NOISE IN SCINTIGRAPHIC IMAGES
}

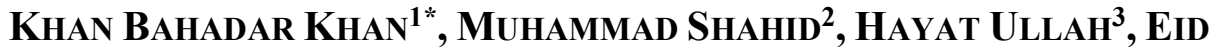 \\ REHMAN $^{4}$ AND MUHAMMAD MOHSIN KHAN ${ }^{3}$ \\ ${ }^{I}$ Department of Telecommunication Engineering, University College of Engineering \\ \&Technology (UCE \&T), The Islamia University, Bahawalpur, Pakistan. \\ ${ }^{2}$ The Istituto Italiano di Tecnologia - IIT, \\ PAVIS - Pattern Analysis and Computer Vision Lab, Italy. \\ ${ }^{1,3}$ Department of Electrical Engineering, \\ ${ }^{4}$ Department of Computer Science \& Software Engineering, \\ International Islamic University, Islamabad, Pakistan.
}

*Corresponding author: kb.khattak@gmail.com

(Received: $21^{\text {st }}$ March 2017; Accepted: $6^{\text {th }}$ March 2018; Published on-line: $1^{\text {st }}$ Dec 2018)

https://doi.org/10.31436/iiumej.v19.i2.835

\begin{abstract}
A 2-D Adaptive Trimmed Mean Autoregressive (ATMAR) model has been proposed for denoising of medical images corrupted with Poisson noise. Unfiltered images are divided into smaller chunks and ATMAR model is applied on each chunk separately. In this paper, two $5 \times 5$ windows with $40 \%$ overlap are used to predict the center pixel value of the central row. The AR coefficients are updated by sliding both windows forward with $60 \%$ shift. The same process is repeated to scan the entire image for prediction of a new denoised image. The Adaptive Trimmed Mean Filter (ATMF) eradicates the lowest and highest variations in pixel values of the ATMAR model denoised image and also average out the remaining neighborhood pixel values. Finally, power-law transformation is applied to the resultant image of the ATMAR model for contrast stretching. Image quality is judged in terms of correlation, Mean Squared Error (MSE), Structural Similarity Index Measure (SSIM) and Peak Signal to Noise Ratio (PSNR) of the image with latest denoising techniques. The proposed technique showed an efficient way to scale down Poisson noise in scintigraphic images on a pixel-by-pixel basis. The highest correlation 0.9706, PSNR 10.023 and MSE 25.902 is achieved by the proposed technique.
\end{abstract}

ABSTRAK: Model 2-D Auto-Pengurangan Purata Potongan Penyesuaian (ATMAR) telah dicadangkan bagi menghilangkan gelombang bunyi yang dicemari pada imej perubatan dengan bunyi Poisson. Imej yang tidak ditapis ini telah dibahagikan kepada pecahan kecil dan model ATMAR telah diadaptasi bagi setiap pecahan. Dalam kajian ini, dua $5 \times 5$ kotak tetingkap dengan $40 \%$ pertindihan telah digunakan bagi mendapatkan nilai tengah piksel pada barisan tengah. Pekali AR telah dikemas kini dengan meluncurkan kedua-dua kotak tetingkap ke hadapan dengan $60 \%$ perubahan. Proses yang sama telah diulang dengan mengimbas imej keseluruhan bagi mendapatkan imej yang telah dinyahbunyi. Tapisan Purata Potongan Penyesuaian (ATMF) ini menghilangkan perubahan paling bawah dan paling atas dalam nilai piksel imej model ATMAR yang dinyahbunyi dan menyama-rata saki-baki nilai piksel bersebelahan. Akhir sekali, perubahan cara-kuasa telah diadaptasi pada imej akhir model ATMAR bagi regangan ketara. Kualiti imej telah dinilai dari sudut korelasi, Kesalahan Purata Kuasa Dua (MSE), Indeks Ukuran Persamaan Struktur (SSIM) dan Signal Puncak kepada Nisbah Bunyi (PSNR) melalui kaedah terkini nyah-bunyi pada imej. Teknik ini menunjukkan cara berkesan bagi menurunkan bunyi Poisson pada imej saintigrafik pada asas piksel-kepada- 
piksel. Korelasi tertinggi adalah 0.9706, PSNR 10.023 dan MSE 25.902 telah dicapai melalui teknik yang dicadangkan.

KEYWORDS: denoising; autoregressive model; Poisson noise; adaptive trimmed mean

\section{INTRODUCTION}

Scintigraphic or nuclear images allow investigation of the human body by injecting photons from radioactive products and detecting its radiation time. The radioactive product that is associated with a labelled biological molecule is called a tracer that gathers in the organ/tissue of interest after an injection into the blood. The planar gamma camera can be used for capturing radiation emitted by the radioactive product, this imaging technique is called scintigraphy [1]. In nuclear medicine, scintigraphic images are used for investigation of some organs, regardless of their poor resolution. Poisson noise is one of the important sources of deterioration in scintigraphic images [2]. Numerous techniques have already been used for reduction of Poisson noise in scintigraphic and Single Photon Emission Computed Tomography (SPECT) images. The degradation in quality of such tomographic images is caused by detection efficiency, attenuation, collimator correction, and scatter of gamma rays.

These factors cause the output image to have low contrast, high noise levels, and poor spatial resolution [3]. In tomography, filtering techniques are considered very important for image enhancement. Reduction of noise can be achieved before reconstruction, which is called pre-filtering, or during or after reconstruction, which is known as post-filtering [4].

Adaptive autoregressive (AR) filters can be used for removal of Poisson noise in scintigraphic images [5]. The AR filter is further improved to scale down noise from 3-D reconstructed data of scintigraphic images and also from SPECT images [6]. It is important to apply the best AR filter for the projection data of scintigraphic images, because a small change in the projection data may cause a large change in the estimated transaxial image [6].

\section{SCINTIGRAPHIC IMAGE ACQUISITION}

The Gamma camera invented by Anger is used for capturing radiation emitted by the radioactive product [7]. The main components of the gamma-camera for scintigraphic image acquisition are discussed in the following subsections.

\subsection{The Collimator}

The collimator puts gamma rays in one direction to reach the crystal; unlike light, gamma rays cannot be concentrated using lenses [8]. Incoming gamma rays can be sensed by the collimator and the light generated by the cooperation of the gamma rays and crystal can be converted into an electronic signal by photomultiplier (PM) tubes and preamplifiers [9]. Parallel hole, pinhole, converging, and diverging are all different types of collimator. The most popular collimator is the parallel-hole collimator, which retains the dimensions of an image. In the case of non-parallel collimators, the divergence or convergence nature of the collimator and geometrical disposition are the controlling factors of an image dimension and the cause of geometric distortion [7]. Holes are detached by the lead "walls" are called septa. Resolution/sensitivity depends on the collimator thickness, hole diameter, and septal thickness. Generally, the collimator thickness is 0.3-1.4 millimeters and the hole diameter is 1.8-3.4 millimeters [10]. 


\subsection{The Scintillator Crystal}

In the gamma camera, crystals usually consist of thallium-activated sodium iodide (NaI (T1)). Edges and the front side can be protected from outside moisture and light by coating it with a thin aluminum (Al) layer. Atomic number $(\mathrm{Z})$ and high mass density make the crystal desirable. Important properties of the crystal are high energy resolution, high detection efficiency, and low decay constant time [11,12]. Crystals generally having a thickness of about $1 \mathrm{~cm}$ can detect photons with energies up to a few hundred $\mathrm{keV}$. The energy accumulated in the crystal is proportional to the number of light photons produced by interaction of crystal and gamma rays. The light guide of the glass is optically coupled to the rear side of the crystal, which protects the crystal and directs the light photons to an array of photomultiplier tubes [10].

\subsection{The Photomultipliers (PM) Tubes}

The PM tube is responsible for converting photon energy diffused by the crystal to an electrical signal [11]. This is accomplished by the consolidation of several elements placed in a vacuum to permit the flow of electrons. The first element is a photocathode placed in connection with the crystal. Light photons extract electrons on metal foil on the photocathode. These electrons are taken captive to the first dynode due to the application of a high voltage between positively charged and the photocathode. The electrons' expedition sanctions them to extract a much more immensely colossal number of electrons from the dynode. The same phenomenon is repeated on several other cascading dynodes [13].

\section{PROPOSED MODEL}

The proposed model consists of three major steps: an Autoregression (AR) model, Adaptive Trimmed Mean Filter (ATMF), and a power-law transformation. Fig. 1 shows a step-wise block diagram of the proposed technique. The steps of the proposed method are as follows:

1. Two $5 \times 5$ windows with a $40 \%$ overlap are used to predict the center pixel value of each corresponding window.

2. AR coefficients for both windows are calculated using a Forward Backward Prediction (FB) method as shown in equations (2) and (3).

3. Using corresponding AR coefficients and neighborhood pixels of each window to predict the central pixel value according to equation (1).

4. Using average of AR coefficients of both $5 \times 5$ windows to predict the pixel value of the overlapping region.

5. Slide both windows forward with a $60 \%$ shift and update AR coefficients by following step 2 .

6. Repeat steps 2 through 5 to scan the complete noisy image and update their predicted values denoted by $X \_$pred.

7. $X \_$err is calculated by using equation (4) to preserve edges and getting predicted image $I$ pred.

8. Now, a $7 \times 7$ window of AR denoised image $\left(X \_\right.$pred $)$is taken, slid pixel-by-pixel.

9. The mean and variance for each $7 \times 7$ individual window is calculated. The overall variance from local variance is computed.

10. The adaptive mean of an image is computed using equation (5) to make boundaries prominent on its true position.

11. The pixel values of the $7 \times 7$ window are arranged in ascending/descending order, the ten upper and ten lower outlier pixels are trimmed and the mean of the remaining 
pixels is computed using equation (6). Ten pixels are trimmed on both sides as it gives good results after performing different experiments with trimming a different number of pixels.

12. The power law transformation is applied using equation (7) for contrast stretching to improve the visual quality of the image.

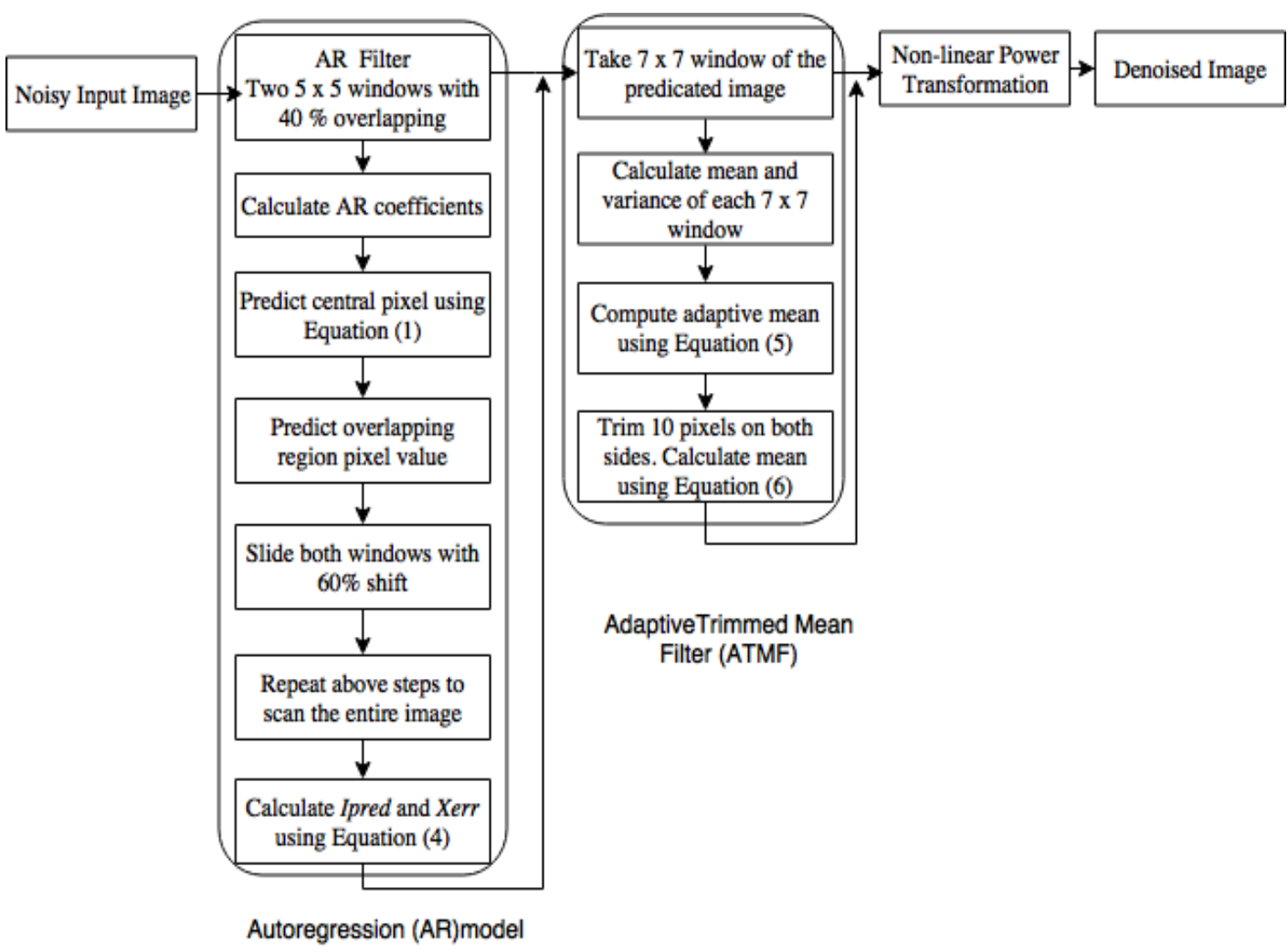

Fig. 1: Block diagram of the proposed denoising model.

\subsection{AR Model}

In the first step, the AR model filter is applied in which each pixel of the image is regressed on its neighborhood pixel values called the prediction region in AR model. The variable of interest in the AR model is predicated using linear combination of the surrounding values of the variables. The AR models are linear prediction models that split an image into two additive components, a predictable image and a prediction error image. In the AR model, no past values of the model input are used [14]. In this research, a new 2dimensional adaptive autoregressive model for filtering of scintigraphic images is introduced. An AR process $X\left(n_{1}, n_{2}\right)$ can be expressed as [15].

$$
X_{\text {Pred }}\left(n_{1}, n_{2}\right)=-\sum_{k_{1}} \sum_{k_{2}} a\left(k_{1}, k_{2}\right) X_{n o i s y}\left(n_{1}-k_{1}, n_{2}-k_{2}\right)+w\left(n_{1}, n_{2}\right)
$$

where $a\left(k_{1}, k_{2}\right)$ are the weighting coefficients, indices $k_{1}$ and $k_{2}$ define the type of prediction region in a two dimensional array $\left(n_{1}, n_{2}\right)$ matrix, and $w\left(n_{1}, n_{2}\right)$ represents prediction error, that is, the difference between the original value and the predicted value in this pixel. Predicted image $X_{\text {Pred }}$ is the image obtained by applying the AR model on the original image $X_{\text {noisy }}$. AR coefficients for both windows are calculated using a Forward Backward Prediction (FB) method. 
In scintigraphic images, the same model cannot be applied to the entire image as it consists of large local spatial variations, therefore, the model must be adapted according to the variations. That is why the image is divided into smaller chunks and the AR model is separately applied to each chunk. In this method, two 5 x 5 windows with a $40 \%$ overlap are used to predict the pixel value of the central row. If more or less than $40 \%$ overlap ratio is selected, the predicted values will come closer to the previous or next pixel values. In order to keep a balanced correlation with the previous and next pixel values, this overlapping ratio is selected experimentally. The AR coefficients on both windows are computed using a Forward Backward Prediction (FB) method as follows.

The forward predictor model predicts a sample $x(m)$ from a linear combination of $P$ past samples $x(m-1), x(m-2), \ldots, x(m-P)$.

$$
\tilde{x}(m)=\sum_{k=1}^{P} a_{k} x(m-k)
$$

where the integer variable $m$ is the discrete time index, $\tilde{x}(m)$ is the prediction of $x(m)$, and $a_{k}$ are the predictor coefficients.

Similarly, we can define a backward predictor, that predicts a sample $x(m-P)$ from $P$ future samples $x(m-P+1), \ldots, x(m)$ as

$$
\tilde{x}(m-P)=\sum_{k=1}^{P} c_{k} x(m-k+1)
$$

where the integer variable $m$ is the discrete time index, $\tilde{x}(m-P)$ is the prediction of $x(m-P)$, and $c_{k}$ are the predictor coefficients.

Using corresponding AR coefficients and four closest neighborhood pixels of the window to predict the central pixel value according to equation (1), both windows are slid forward with $60 \%$ shift and AR coefficients are updated. The same process is repeated to scan the whole image for prediction of the new denoised image. The AR model changes the nature of Poisson distribution somehow, which looks like a Gaussian distribution. Adaptive Trimmed Mean Filter (ATMF) is applied to the resultant image, which gives better results in terms of reduction in Poisson noise.

$X_{\text {err }}$ is calculated by following equation to preserve edges.

$$
X_{\text {err }}=X_{\text {noisy }}-X_{\text {pred }}
$$

where $X_{\text {noisy }}$ is the noisy image, $X_{\text {pred }}$ is the predicted image and $X_{\text {err }}$ is the prediction error image. The error image is averaged out by using the averaging filter to sum up with the predicted image for edge enhancement.

An example of a two blocks with $40 \%$ overlapping is represented in Fig 2. 


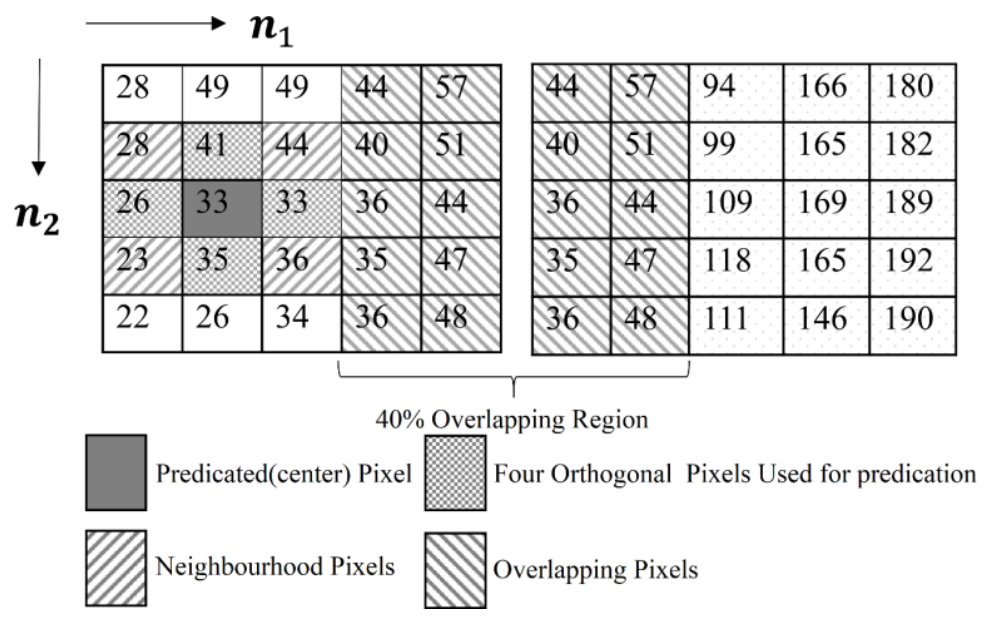

Fig. 2: Hatched area of 2-dimensional autoregressive model.

\subsection{Adaptive Trimmed Mean Filter (ATMF)}

ATMF is applied to the output denoised image of the AR process. The aim of applying ATMF is to remove lowest and highest variations in the pixel values and average out the remaining neighborhood pixel values. The whole image is divided into $7 \times 7$ smaller blocks and the local mean and variance of each block are computed. ATMF for an $m \times n$ image is given by the expression: [16]

$$
g(i, j)=f(i, j)-\frac{\sigma^{2}{ }_{n}}{\sigma^{2}{ }_{L}}\left[f(i, j)-U_{L T}\right]
$$

where $g(i, j)$ and $f(i, j)$ represent the output and input images, respectively. The $U_{L T}$ is the local trimmed mean, $\sigma^{2}{ }_{n}$ is the overall noise variance, and $\sigma^{2}{ }_{L}$ is the local noise variance. If $\sigma^{2}{ }_{n}$ is close to zero, it produces an output very close to the input image $f(i, j)$. Likewise, if $\sigma^{2}{ }_{L} \gg \sigma_{n}^{2}$ it also produces an output pixel close to $f(i, j)$. Otherwise, this filter outputs a pixel close to the local average. $U_{L T}$ for an $m \times n$ image is given by expression in: [16]

$$
U_{L T}=\frac{1}{m n-\propto} \sum_{(x, y) \in N_{i j}} f^{\prime}(x, y)
$$

where $\propto$ is the total number of maximum brightest and darkest trimmed pixels and $f^{\prime}(x, y)$ is the sum of remaining pixels. ATMF removes abnormal pixel variations, preserves boundaries at their true position, and also removes blurriness effects [17].

\subsection{Power-Law Transformation}

The power-law transformation is applied to the resultant image of the ATMF for contrast stretching and to improve visual quality. The power-law transformation can be expressed as follows [17]:

$$
s=c r^{\gamma}
$$

where $c$ and $\gamma$ are positive constants having values 1 and 3 respectively and $r$ is pixel intensity value of the image.

\section{SIMULATION AND DISCUSSION}

The proposed model is applied on artificial scintigraphic images having different image statistics corrupted with Poisson noise. The AR model provides a good result with $40 \%$ 
overlap but at the cost of some blurring in the image, which is further improved by applying the ATMF. Power-law transformation is applied for contrast stretching. This technique maintains the high resolution and also preserves the edges along with the noise reduction. The efficiency of the proposed technique is compared with the AR combination of median and Wiener filter and advanced filter, i.e. Non Local Mean (NLM) filter [18] in terms of visual quality, correlation, MSE, PSNR and SSIM. The proposed technique produced better results in terms of edge preservation though the AR process \& adaptive trimmed mean filter produced a smoothing effect, while the edge loss is observed in the case of the conventional filters such as median filters. The quantitative performance measures such as correlation, MSE, PSNR and SSIM are used to check the performance of Poisson noise reduction filtering techniques. Experimental results show that the proposed technique performs significantly well than many other conventional \& recent filtering techniques like median, Wiener and NLM filters, respectively. The aim of scintigraphic image filtering is to restrain statistical noise while sustaining contrast and spatial resolution [19]. The proposed technique simultaneously provides both efficient noise reduction and good spatial resolution for scintigraphic images.

A renal scintigraphic image, artificial scintigraphic image, and transaxial slice of the Zubal phantom [20], denoised by the proposed model and other comparative methods, are shown in Fig. 3, Fig. 4 and Fig. 5, respectively. The proposed method shows good visual results.

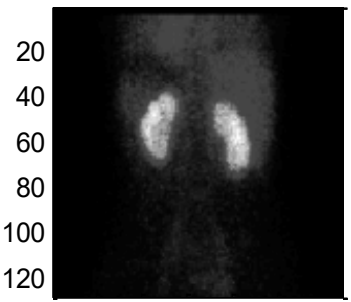

20406080100120

(a)

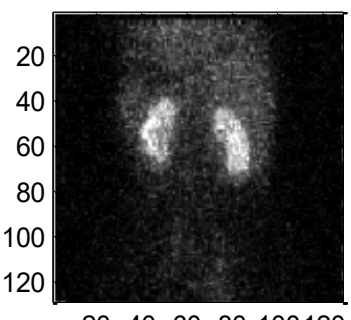

(d)

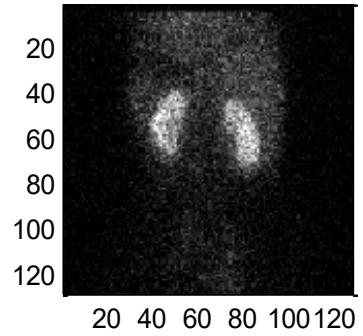

(b)

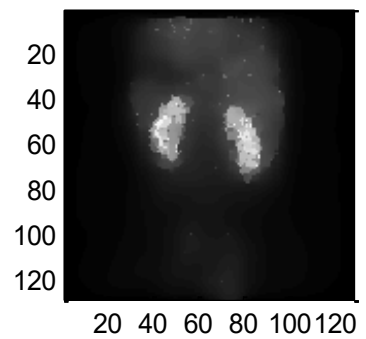

(e)

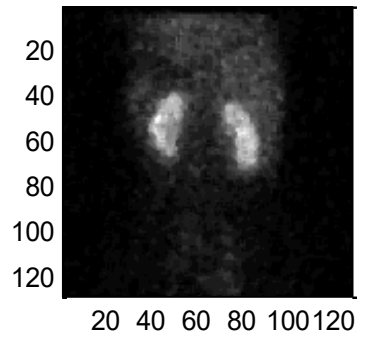

(c)

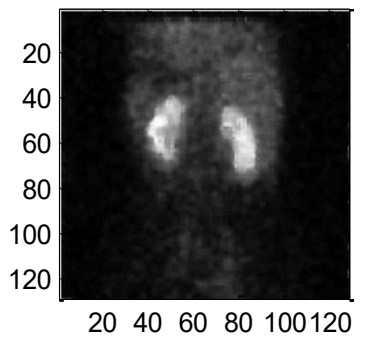

(f)

Fig. 3: Renal scintigraphic image (a) Noise-free image (b) Noisy image (c) Denoised image by median filter with combination of AR model (d) Wiener filter with combination of AR model (e) NLM Filter (f) Proposed technique. 


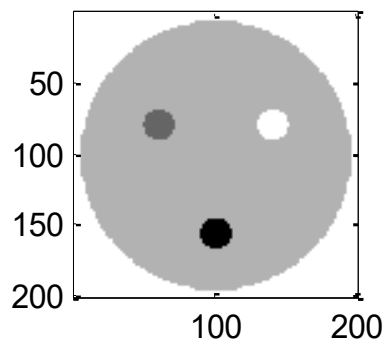

(a)

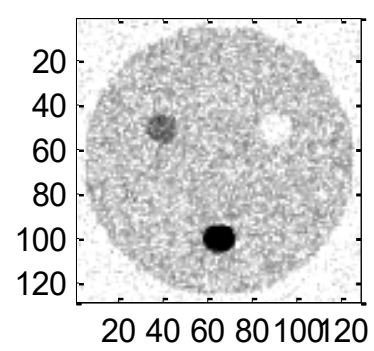

(d)

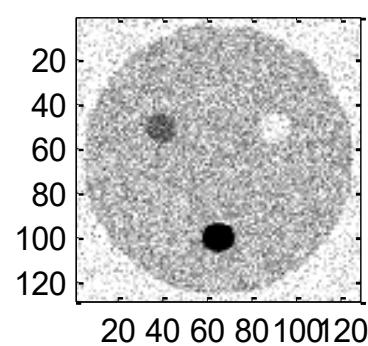

(b)

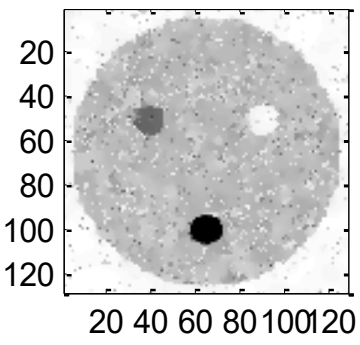

(e)

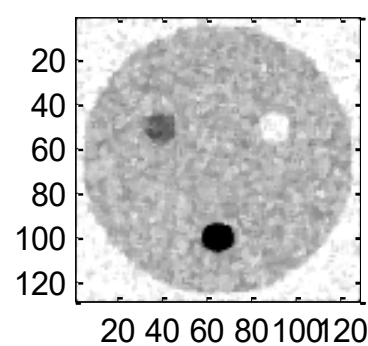

(c)

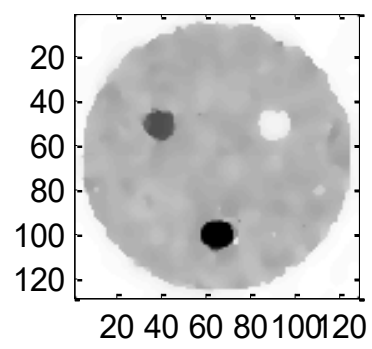

(f)

Fig. 4: Artificial scintigraphic image (a) Noise-free image (b) Noisy image (c) Denoised image by median filter with combination of AR model (d) Wiener filter with combination of AR model (e) NLM Filter (f) Proposed technique.

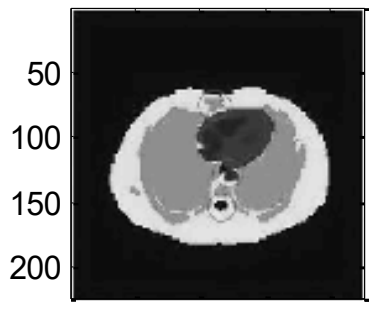

50100150200

(a)

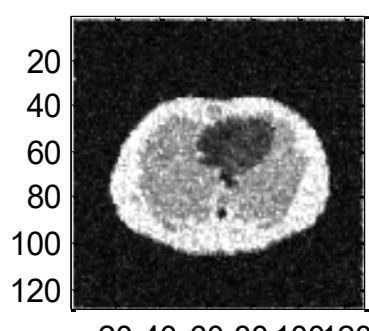

(d)

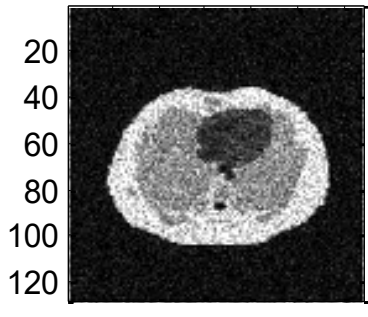

20406080100120

(b)

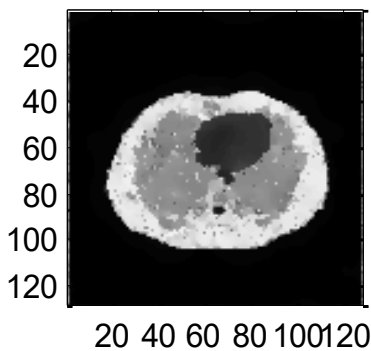

(e)

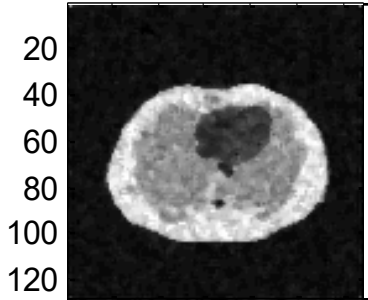

20406080100120

(c)

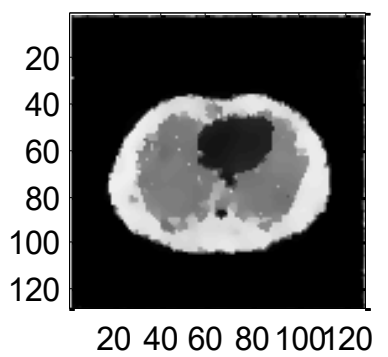

(f)

Fig. 5: Transaxial slice of the Zubal phantom (a) Noise-free image (b) Noisy image (c) Denoised image by median filter with a combination of AR model (d) Wiener filter with a combination of AR model (e) NLM Filter (f) Proposed technique.

The proposed model performed significantly better than other conventional filters in terms of correlation, MSE, PSNR and SSIM shown as coexistent graphical plots with those obtained from median, Wiener filter combined with AR and NLM filter in Fig. 6, Fig. 7, Fig. 8 and Fig. 9, respectively. The SSIM index showing similarity between two images, 
while considering one image as perfect quality to measure the quality of another. The results from the proposed model show that it is better in suppressing the Poisson noise and improving the PSNR and MSE compared to conventional filters.

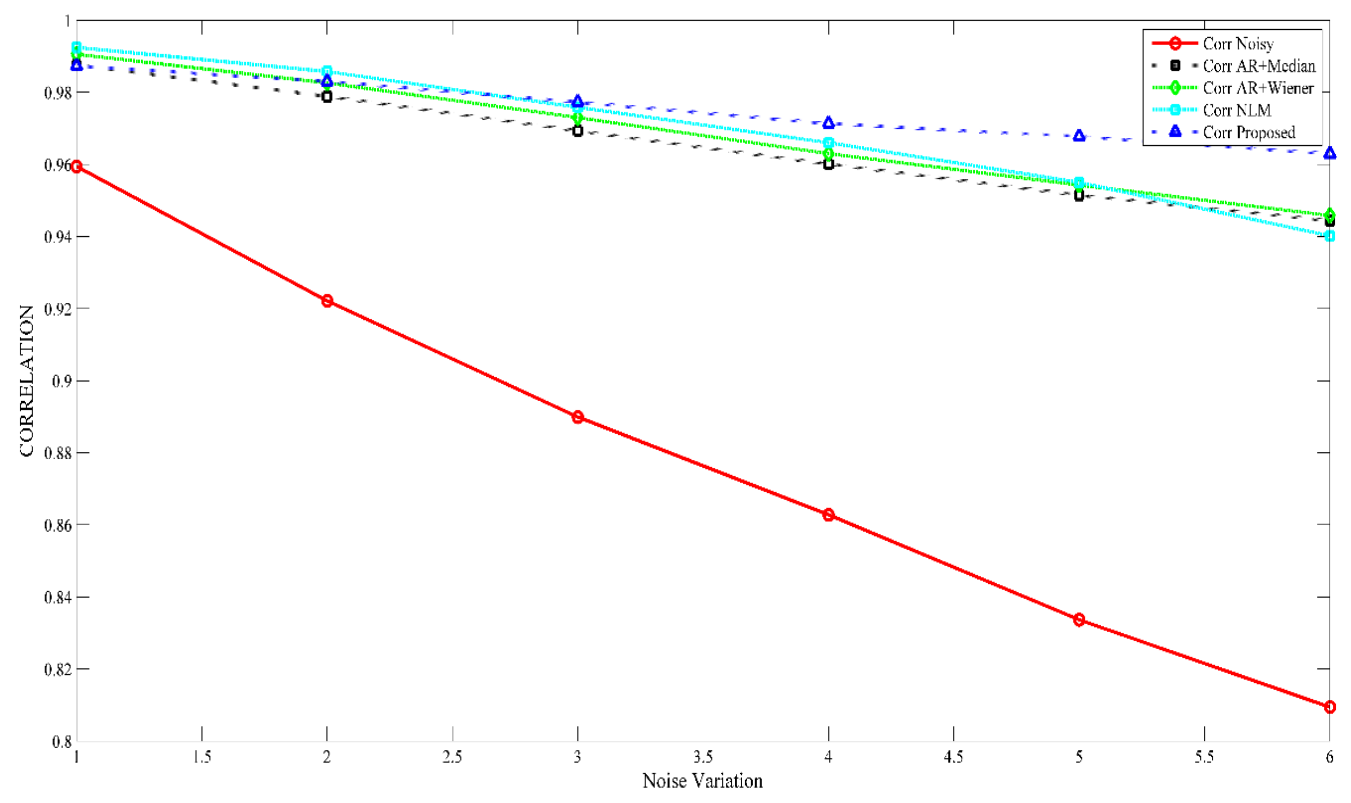

Fig. 6: Correlation comparison of noisy image, median + AR, Wiener $+A R$, NLM and the proposed method.

Figure 6 shows the correlation comparison of the proposed method with median + AR, Wiener + AR and NLM filter. The graph clearly shows that the proposed method produced much better results than median + AR, Wiener + AR and NLM filter at high noise. NLM shows a good result at low noise but as noise varies from low to high, its results degraded. The graph is computed for different noise variations.

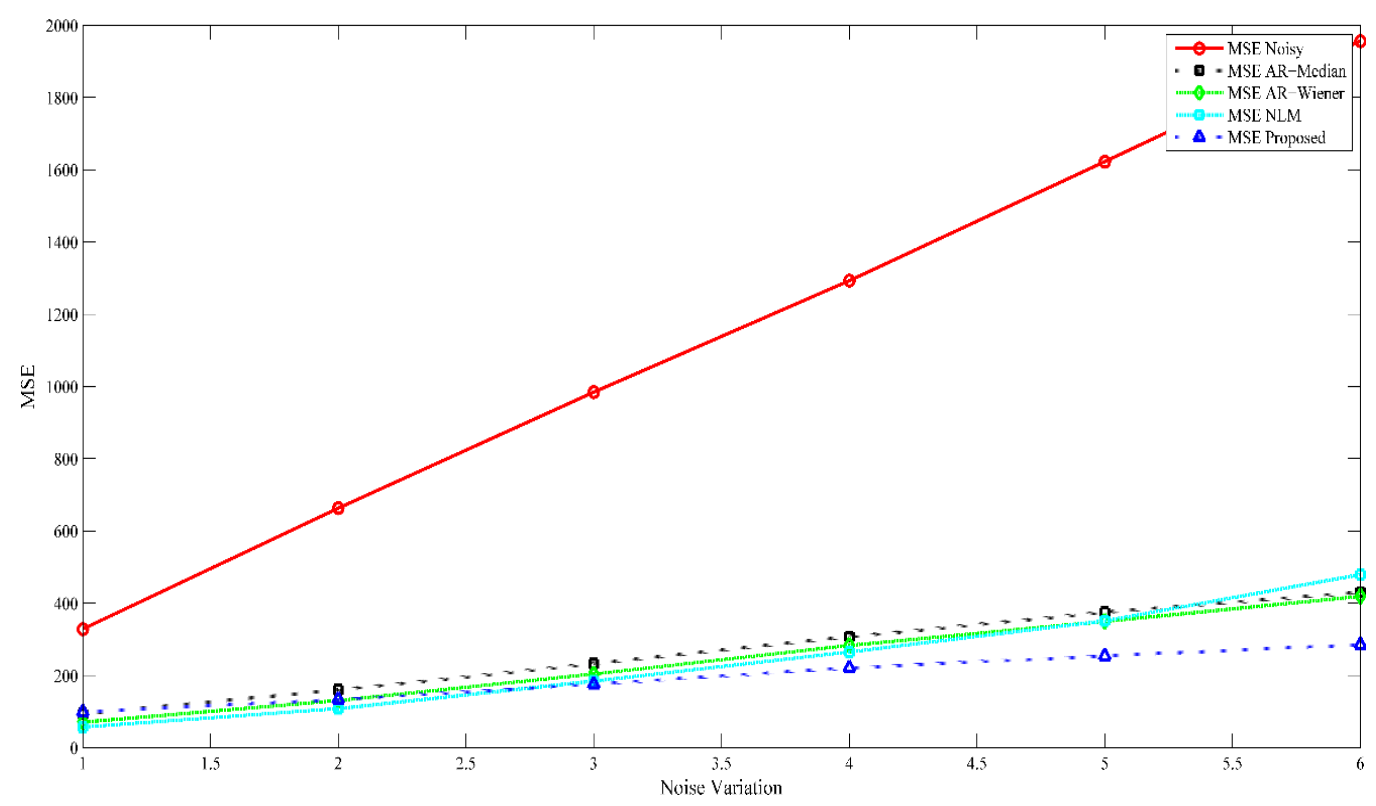

Fig. 7: MSE comparison of noisy image, median + AR, Wiener + AR,

NLM and the proposed method. 
Figure 7 is plotted for MSE comparison of the original and the denoised image [17]. The MSE result of the proposed method is significantly better than median, Wiener combined with AR, and NLM filters. MSE is represented mathematically as

$$
M S E=\frac{1}{m \times n} \sum_{i=0}^{m-1} \sum_{j=0}^{n-1}[f(i, j)-g(i, j)]^{2}
$$

where $f(i, j)$ and $g(i, j)$ represent pixel value at coordinate $(i, j)$ of an image $f$ and $g$. Number of rows and columns are represented by $m$ and $n$.

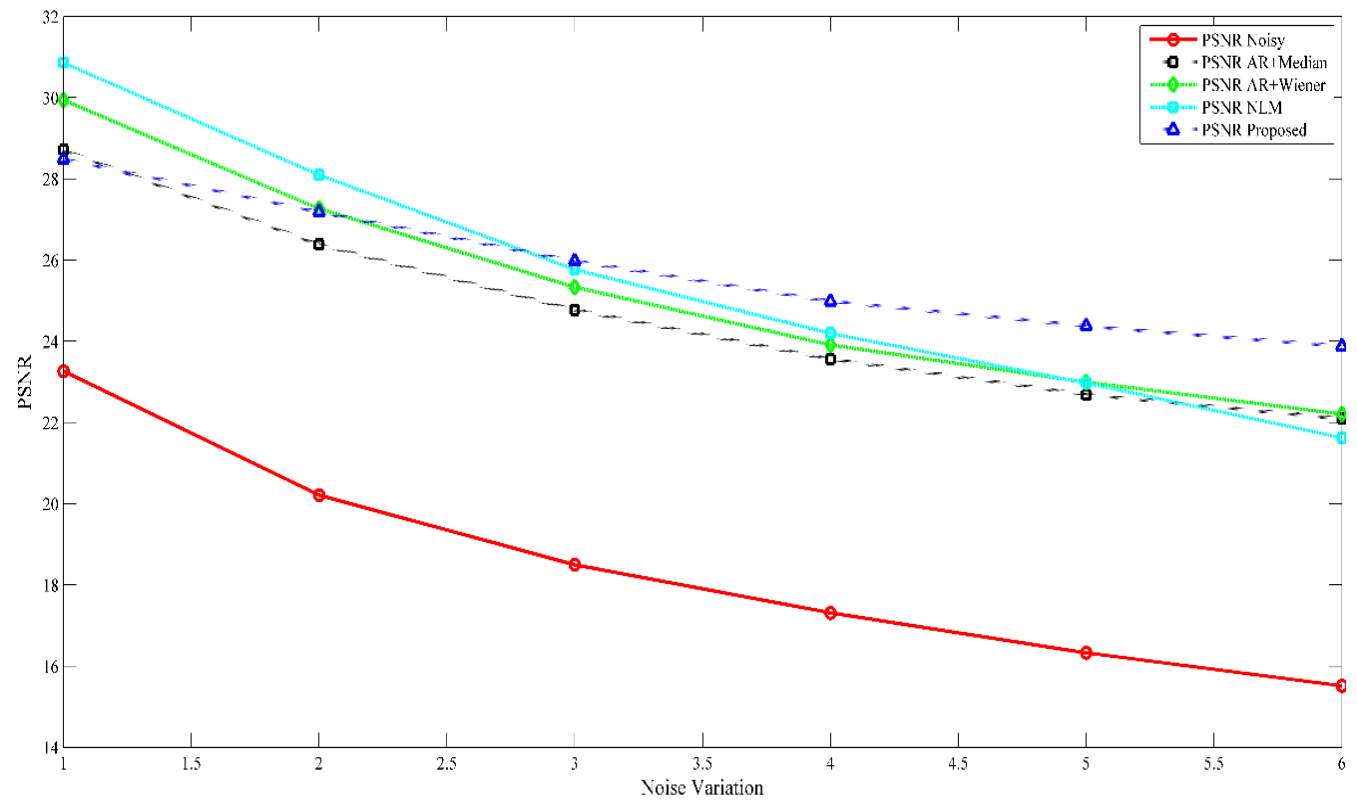

Fig. 8: PSNR comparison of noisy image, median + AR, Wiener + AR, NLM and the proposed method.

Figures 8 and 9 show PSNR and SSIM comparison of the proposed method with other methods on different noise variation. The graph clearly shows that the proposed model is more efficient than other compared methods. The aim of the proposed method is to deal with the noise at high level. At low level noise, the conventional filters, e.g., Median and Weiner filter perform well but they are failed to eradicate high variation of noise. One can easily eliminate low level noise by simply using these conventional filters. The proposed method is specifically designed to deal with the high variation of noise. That is the reason that the proposed method beats all other methods at a high level of noise. Table 1 validated that the proposed method achieved the highest performance in term of MSE, PSNR, and Correlation.

Table 1. MSE, PSNR and Correlation comparison with different methods

\begin{tabular}{cccccc}
\hline Metrics & $\begin{array}{c}\text { Noisy } \\
\text { image }\end{array}$ & $\begin{array}{c}\text { Median }+ \\
\text { AR filter }\end{array}$ & $\begin{array}{c}\text { Wiener + AR } \\
\text { Filter }\end{array}$ & NLM Filter & Proposed \\
\hline MSE & 57.440 & 66.985 & 62.277 & 40.834 & 25.902 \\
PSNR & 6.0206 & 7.3206 & 7.9217 & 8.3450 & 10.023 \\
Correlation & 0.6976 & 0.9428 & 0.9097 & 0.9536 & 0.9706 \\
\hline
\end{tabular}




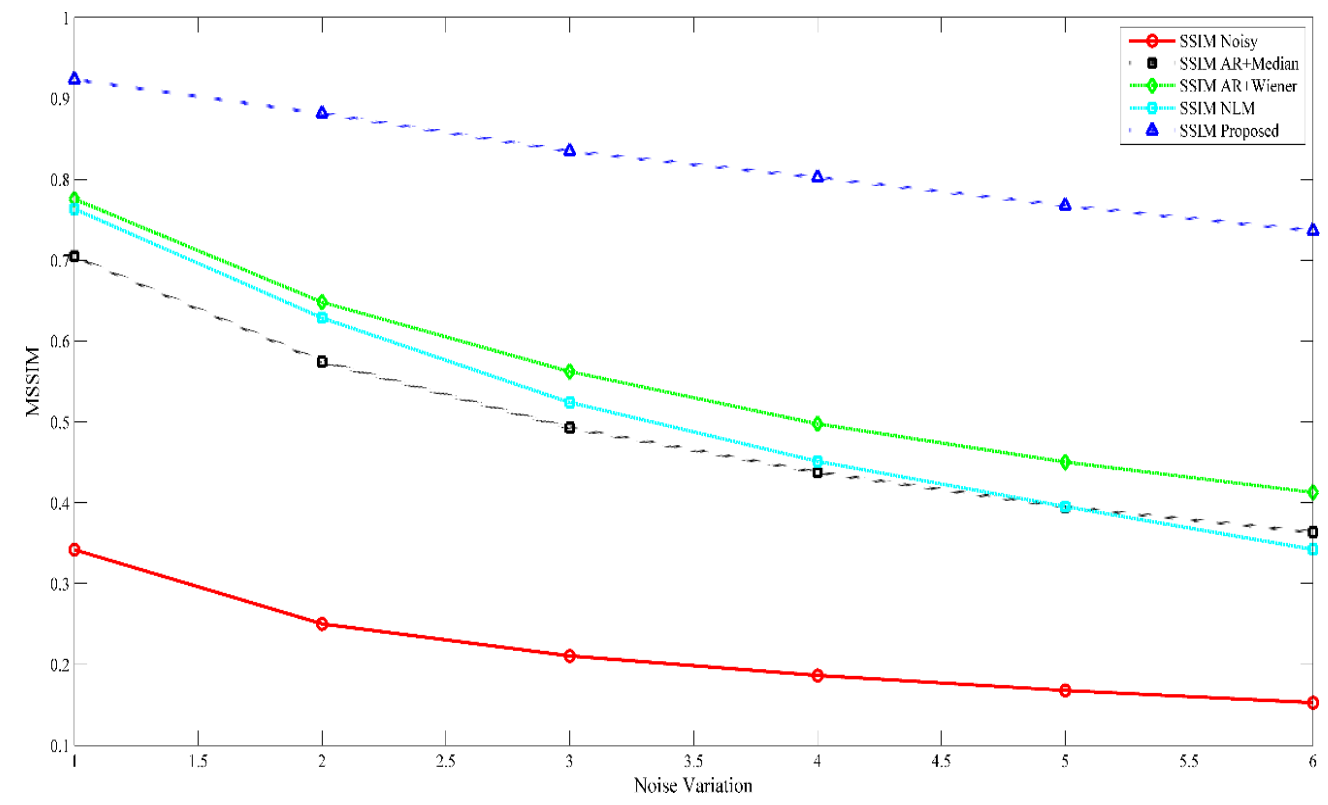

Fig. 9: SSIM comparison of noisy image, median + AR, Wiener $+A R$, NLM and the proposed method.

\section{CONCLUSION}

The proposed model shows an efficient way to scale down the Poisson noise in scintigraphic images on a pixel-by-pixel basis. Edge preservation through calculation of error image $X_{\text {err }}$ after the predicted image through AR model and smoothening through ATMF to remove lowest and highest variations in pixel values, are the major contributions of this research work.

\section{REFERENCES}

[1] Hamrouni K, Khalifa N. (2006) Two Methods for Analysis of Dynamic Scintigraphic Images of the Heart. Int. Arab J. Inf. Technol., 3(2):118-125.

[2] Nawres K, Kamel H, Noureddine E. (2006) Image denoising using wavelets: a powerful tool to overcome some limitations in nuclear imaging. In Information and Communication Technologies (ICTTA'06), 2nd, vol. 1, 2006:1114-1118. IEEE.

[3] Tsui BM. (1996) The AAPM/RSNA physics tutorial for residents. Physics of SPECT. Radiographics, 16(1):173-183.

[4] Kangasmaa TS, Kuikka JT, Vanninen EJ, Mussalo HM, Laitinen TP, Sohlberg AO. (2011) Half-time myocardial perfusion SPECT imaging with attenuation and Monte Carlo-based scatter correction. Nuclear Medicine Communications, 32(11):1040-1045.

[5] Takalo R, Hytti H, Ihalainen H. (2011) Adaptive autoregressive model for reduction of poisson noise in scintigraphic images. Journal of Nuclear Medicine Technology, 39(1):1926.

[6] Takalo R, Hytti H, Ihalainen H, Sohlberg A. (2015) Adaptive autoregressive model for reduction of noise in SPECT. Computational and Mathematical Methods in Medicine. Volume 2015.

[7] Anger HO. (1964) Scintillation camera with multichannel collimators. Journal of Nuclear Medicine, 5(7):515-531.

[8] Kharfi F. (2013) Principles and Applications of Nuclear Medical Imaging: A Survey on Recent Developments. Edited by Faycal Kharfi, 2013: 1.

[9] Mihailidis D. (2012) Nuclear Medicine Physics: The Basics. Medical Physics, 39(10):65256525 . 
[10] De Lima JJ. (ed) (2010) Nuclear Medicine Physics. Taylor \& Francis.

[11] Jonasson T. (2003) Revival of a Gamma Camera. Master of Science thesis, Royal Institute of Technology, Stockholm.

[12] Ritenour, E. Russell. (2009) Principles and Advanced Methods in Medical Imaging and Image Analysis." Medical Physics 36, no. 4, 1460-1460.

[13] Makhlouf F, Besbes H, Khalifa N, Ben Amar C, Solaiman B. (2013) Planar Scintigraphic Images Denoising. Open Journal of Medical Imaging. 3, 116-124.

[14] Marzetta T. (1980) Two-dimensional linear prediction: Autocorrelation arrays, minimumphase prediction error filters, and reflection coefficient arrays. IEEE Transactions on Acoustics, Speech, and Signal Processing, 28(6):725-733.

[15] Haykin SS. (2008) Adaptive Filter Theory. Pearson Education India.

[16] Oten R, de Figueiredo RJP. (2004) Adaptive alpha-trimmed mean filters under deviations from assumed noise model. IEEE Transactions on Image Processing, 13(5):627-639.

[17] Gonzales RC, Woods ER. (2007) Digital Image Processing, 3rd edition. Prentice Hall.

[18] Khursheed S, Khaliq AA, Shah JA, Abdullah S, Khan S. (2014) Third Order NLM Filter for Poisson Noise Removal from Medical Images. MAGNT Research Reviews, 2(7):482-489.

[19] Lyra M, Ploussi A. (2011) Filtering in SPECT image reconstruction. Journal of Biomedical Imaging, volume 2011, 10.

[20] Zubal IG, Harrell CR, Smith EO, Rattner Z, Gindi G, Hoffer PB. (1994) Computerized three-dimensional segmented human anatomy. Medical Physics, 21(2):299-302. 